\title{
Preparing and Managing the Remote Experiment in Education
}

\author{
http://dx.doi.org/10.3991/ijoe.v9i1.2370 \\ T. Kozík, M. Šimon \\ Constantine the Philosopher University, Nitra, Slovakia
}

\begin{abstract}
Remote laboratories have become a real fact in recent years not only at technical universities, but also at lower educational levels. The use of such technology in education is not associated only with the advantages. The attention of pedagogical research is necessary to focus also to some specific problems, pitfalls and risks that occur as a side effect. The development and operation of remote laboratories requires certain resources. Some experiments are able to run fully automatically, others require constant human interference on the spot. What has been overlooked the developers and users of remote experiments was the question how to manage the long-term operation, reliability and innovation of the remote real experiments installed at remote laboratories. In remote experiments, students, consciously or unconsciously, are trying the limit parameters of the experiment. Although such behaviour is important in terms of education, safety of the facilities must be taken into account.
\end{abstract}

Index Terms-Remote experiments. Internet. School experiments.

\section{INTRODUCTION}

Advantages and disadvantages as well as the benefits of remote experiments for teaching practice are well known from the literature [1]-[14]. What has been overlooked and out of the focus among the developers and users of remote experiments was the question how to manage the longterm operation, reliability and innovation of the remote real experiments installed at remote (virtual) laboratories. In extending and improving the experimental base in remote laboratories, besides highly trained educators with the necessary didactic competences and ability to work with information technologies, collaboration of the IT technician of real experiments responsible for the maintenance, management, operation and innovation of the installed experiments is needed. If there is no opening of such a position in the organizational structure of educational organizations operating a remote laboratory, then it can easily happen that the efforts of the developers of experiments, as well as the funds used for the development and research involving the preparation of experiments will fail to produce expected educational and research benefits and the remote laboratory will gradually stop working.

\section{CHARACTERISTICS OF THE REMOTE LABORATORY}

The idea of implementing controlled lab through the Internet for educational purposes can be traced back to the nineties, when Aburdene et al. [2] suggested a futuristic solution for sharing laboratory equipments through the Internet.
According to $\mathrm{Ma}$ and Nickerson [9], remote laboratories are characterized by mediated reality. Similarly to real laboratories, they also need space and laboratory equipment. They differ, however, in the distance between the experiment and experimenter.

Also other authors [3] [8], [14] describe remote laboratories as a situation where management and observation of real devices and objects are mediated by computers, and the needed remote access is provided via a computer network. Thanks to the computer networks, it is possible to access the remote lab from any computer on the Internet.

According to the used technology, remote laboratories can be divided into two groups. The first group is based on specialized client-server applications. This is the way the industrial applications, where it is needed identification of the remote user and recording of his activities, are used, too. A major disadvantage of this solution is the need to install specialized applications for the client - student. This can be very tedious especially on slower networks and it discourages many users from the very beginning.

For the fear virus transmission, users often struggle to download and install the application into their computers. And some institutions even do not allow it [7].

This group can include unique hardware and software solutions. They are operated their mostly by university departments that have decided to go their own way. The quality can vary and, unfortunately, they are accessible on the Internet for relatively short time.

The second group of laboratories is based on the standard Internet technologies. The advantage is that on the client - student side a standard browser with Java technology is sufficient. On the server side there is a web server which by the support of software provides communication with the hardware of the experiment.

\section{PREPARATION OF REMOTE EXPERIMENT}

In preparation of remote experiments we feel two different groups of requirements.

The first group of requirements is formulated by a teacher and his intention to use the remote experiment in education.

The second group of requirements is formulated by the technical solution of remote experiment. Fulfilment of requirements of both groups is a prerequisite for a successful school experiment.

At the beginning of each experiment is the idea of the teacher. The teacher will decide to innovate teaching using own remote experiments. 
Creating a remote experiment, which will meet the requirements for the safe and reliable operation, as well as requirements arising from the didactics of education, is a challenging task. Complexity and specificity of this task requires participation and close cooperation of a team of experts - specialists. Therefore, we consider establishment of such a professional team to be the primary and essential role of the teacher - the holder of the idea of applying the remote experiment in teaching. The mission and objective of the expert team will be to design and carry out the remote experiment. The condition is that the design and the implemented form would meet the technical and educational criteria.

We assume that the established team engaged in the development and operating the remote experiment will consist of at least four specialists.

The leading and advisory personality in the creative team is the teacher who designs an experimental, topically oriented and the subject related task for the remote experiment. The teacher's role is:

[1] to define training and educational objectives to be achieved by applying the remote experiment in teaching,

[2] to design assignments,

[3] to propose a content of theoretical information for the user,

[4] to propose procedures of practical activities in carrying out measurements,

[5] to propose the methods for evaluation of results and the didactical application of experiment in the various stages of the lesson.

Along with designers they define and solve requirements for the environment, in which the remote experiment will be located. They develop a list of all the information that will be provided to the user after logging into the Website of the remote experiment.

The role of IT technician in the team is to carry out technological aspects of the teacher's requirements. S/he solves also the designer's requirements concerning the structure and visual design of the website.

The design engineer is expected to design a technical solution to the arrangement of the measuring apparatus in the remote experiment, together with the design of supporting structures. In cooperation with the IT technician they will design the control and operational components of the experiment in its entire cycle: from launching the experiment to its closing by the user.

So, teacher must discus with designer about design of user environment, with engineer about proposal of construction and with IT technician about remote controlling and monitoring through computer network, Internet.

\section{DIDACTIC USER REQUIREMENTS}

The developer of remote experiment must solve and pay attention to visualisation and the information contents of remote experiment. This must be consistent with the theme of the experiment and with the set educational goals.

The educational impact and its popularity will largely depend on the content and the level of its didactic and technical processing. The user environment of remote experiment must be designed and treated:

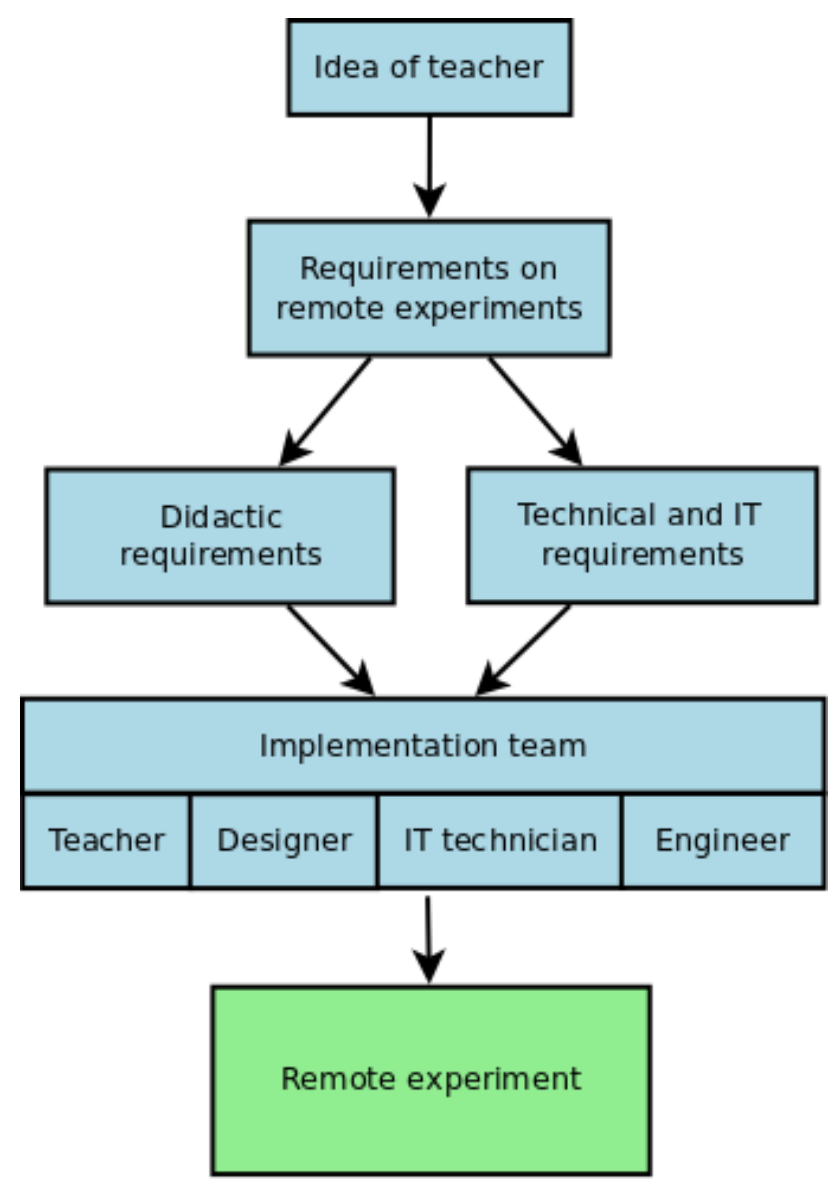

Figure 1. From idea to remote experiment.

- user friendly

- simple and clear navigation for user

- clearly defined assignment and tasks of experiment with established educational objectives

- theoretical background of the experiment

- motivation for students to be creative

At its opening, the users environment should attract the user's attention by its graphical design and gave him an interest in learning about the topic. Important is the way of visualisation of measurement or phenomenon and quality of image transmission of the set of experiment and monitoring its progress. Similarly, it should include theoretical background of the experiment, that the student understands the starting points of experiment and know what its purpose is and why. Whole course of the experiment should be simple and direct. Students should not lose in numbers of non-essential settings.

\section{TECHNICAL REQUIREMENTS ON REMOTE LABORATORIES}

Technical resources, by which the experiment is carried out in remote laboratories of experiments consists of an experimental apparatus with sensors endpoints, whose signals are processed electronically in modules connected with the control and check panel. This panel provides communication between modules, sensors and computer through input-output card of the computer.

In the development and technical solution of the set of the measuring apparatus in the remote experiment, the designer (investigator) gradually comes to: 
- an appropriate selection of sensors for measurement of physical parameters, properties or characterization of the phenomena observed in the processes of the remote experiment,

- the processing of modules with the transmission to the web server where the website of the remotely controlled experiment is located.

In practice, the user proceeds so that on the browser selects the website of the remote experiment from the corresponding web server to download all the graphics to the PC to be displayed along with all the texts. The user through the website sends the commands that after evaluation of the web server launch the required operation.

This principle of operation has in some systems of remote experiments incorrect solution and imposes constraints in terms of having to allocate to each remote experiment the own web server with its own IP address and control panel. In case of the decision to place into remote laboratory further experiments, there is a need to install additional web servers with own IP addresses and control panels. Such a solution is demanding not only for technical equipment of the laboratory by further computers, but is associated with the availability of the allocation of public IP addresses.

When designing a laboratory of remote experiments it is important to realize the continuous development of hardware and software. Backwards compatibility is not always obvious. The laboratory should be built on open and widely used standards. It is thus a greater chance that the laboratory will use a platform that will be here in 3-4 years.

Another problem that can occur when operating the remote experiments is linked to an Internet connection. Low bandwidth and transfer rates of "live video stream" will be reflected in reducing the quality of transmitted video. If the arrangement of the remote laboratory experiment is considering the current way of taking images from two video-cameras, then the use two cameras in the design of remote real experiment requires a separate (specific) software solution.

In designing of the experimental base in remote laboratories, besides highly trained educators with the necessary didactic competences and ability to work with information technologies, a collaboration of the IT technician of real experiments is needed. If there is no opening of such a position in the organizational structure of educational organizations operating a remote laboratory, then it can easily happen that the efforts of the developers of experiments, as well as the funds used for the development and research involving the preparation of experiments will fail to produce expected educational and research benefits and the remote laboratory will be gradually abolished.

\section{ADMINISTRATION OF REMOTE EXPERIMENTS}

In remote experiments, students, consciously or unconsciously, are trying the limit parameters of the experiment. Although such behaviour is important in terms of education, safety of the facilities must be taken into account.

In [13] the three levels of protection of remote experiment are reported on the example of the assembled remote experiment of "inverted pendulum". The first level consists of software that sets the controller output to zero when the pendulum reaches a predefined limit. The second level consists of mechanical switches to turn off the power when the set limits are exceeded. The last level is made up of rubber backstops.

The actual experimental facilities should be fully controllable at a distance by an administrator of the remote laboratory. Application controlling the remote experiment has to be robust to avoid the damage of experimental equipment by the potential defective experiment parameters. The input data coming from user must be controlled.

Ferrero et al. [5] besides the others introduces the following requirements for remote laboratories:

- Realism. Students must use the real equipment involved in a real environment, to perceive all aspects of the real experiment. They should have available all the possible settings of the experiment. Possible errors must not be automatically filtered, but the students themselves must detect and correct them. The output measuring should students receive in a similar way and form as in the direct work with real equipment.

- Availability. Access to a remote laboratory should not be limited in time. Students can therefore carry out an experiment in time and from place that suits them best. The need of reserved software for access to the laboratory and processing of outputs must be strictly limited so that students would not be forced to download and install other applications. Under the availability can be considered costs for students and portability. The student must not be required for any other costs than those for the Internet connection. The system of the remote laboratory has not to be language and platform dependent.

- Safety and security. There is need of the remote laboratory equipment safety and security of the information system and its protection against malicious attacks.

- Implementation and maintenance costs. The process of school financing is working in such a way that finding the budget to create a new didactic laboratory is less difficult than budgeting for maintenance.

- Portability. The development of computers, operating systems and software applications are so fast that each application should be both portable and platform independent as possible. This can reduce the cost for future development and possible migration to another system. In this regard, the use of programming languages should be limited to the platformindependent languages such as Java and the like.

Salzmann and Gillet [13] highlight the issue of sustainability of remote laboratories. The main challenge lies in the transition from remote experiments developed in the framework of the research projects to the professionally administrated and managed remote laboratories. Such laboratories would be available worldwide with guaranteed availability for 24 hours a day, seven days a week. Eikaas et al. [4] came up with the idea of the business model (ESP Experiment Service Provider). ESP would offer a set of laboratory experiments to the customers from universities, secondary schools, but also the individuals or companies. The basis would be global access portal and high quality remote experiments. As if it 
was a paid service, $100 \%$ performance and availability would be a necessity.

The issues of sustainability, extensibility and management are discussed in [6]. The team of authors distinguishes technical and pedagogical perspectives. The software development and its management make the framework for technical issues. They draw attention to obsolescence of hardware. If we later need to replace some components, they may already not be available on the market. Equally important is the regular recalibration of laboratory equipment. What concerning the pedagogical perspective, it is important that teachers accept the remote experiment in order to understand its contribution to educational practice. Otherwise, they refuse to use it or the experiment can be used inappropriately.

The correct functionality of remote laboratory requires good management, proper and effective use of technologies. For the whole process it is important to have well-defined plans of management, accountability, monitoring and evaluation. Managing the remote laboratory is a continuous process that does not end by implementing all the necessary hardware and software components. Elements of the laboratory must be constantly monitored and controlled. Their hardware and software components have to be regularly updated by security patches. This process of permanent administration is referred to as configuration management.

Remote laboratories may become the target of computer attacks. Like any network service, also they may become victims of DoS (Denial of Service) attack. To strengthen the overall protection of remote laboratories it is important to improve their safety properties at all levels.

The first task is to prevent an unauthorized entry into the laboratory. Suitable authentication mechanism is the first step to achieve the access control. Authentication is usually enforced by creating user accounts for those users who authenticated by user name and password may access the experiment. This method is most widely used means of authentication. Since the remote laboratory is connected to the Internet, it is necessary to protect it by firewall. Firewall is a tool that separates protected network from unprotected one and, in many cases, one protected part from another unprotected part of the same network. Therefore, it is a certain throttle point, through which all the communication is passed to and from the protected network. With today's sophisticated computer attacks it is necessary to protect the remote laboratory also by another element - an Intrusion Detection System (IDS). The role of the system of intrusion detection is to identify, preferably in real time, an abuse, unauthorized or improper use of a computer system. The issue of intrusion detection has become very important in relation to the increase in the number of systems connected to the Internet. More systems mean more potential attackers and their identification becomes more difficult. An Intrusion Detection System, like other computer security tools should be included in the security policy.

\section{CONCLUSION}

Technological development in information technologies provides many new possibilities for their exploitation in education. Remote and virtual laboratories are now a real fact, not only at technical universities, but also at lower educational levels. Teaching with the support of information technology is popular not only for pupils/students, but also for educators themselves. The use of such technology in education is not associated only with the advantages, but it also brings emerging problems, pitfalls and risks, on the solution of which it is necessary to focus the attention of pedagogical research. The development and operation of remote laboratories requires some resources. Some experiments are able to run fully automatically (usually those from the Electrical Engineering), others require constant human intervention on the spot (this is typical in the chemical experiments). Correct functionality of remote experiments is critically important for its exploitation. As stated in [6], it includes not only technical problems and challenges, but also educational problems. Maintaining remote laboratory experiments can be surprisingly difficult in area of human resources and facilities. This should be considered during the developmental phase of the laboratory. Another hitherto little-examined issue is the integration of remote experiments into the structure of lessons to achieve the desired training and educational impact. Despite these reservations, not only locally but also worldwide, there are currently being discussed issues and paid attention to the preparation and evaluation of remote and simulated experiments and there continues interest in their integration into teaching.

If we want the real remote experiments to become innovative means of educations in schools and a popular teaching aid, it is important and necessary that the preparation and operation of remote experiment should have a spiral nature.

In its basic cycle, the implementation of the ideas of the teacher designer is carried out. The teacher designs an experimental task based on the curricular content, s/he defines the basic requirements for the development and operation of the experiment from technical and didactic perspective. S/he initiates establishment of a work team for preparation and implementation of the experiment. The outcome of the team collaboration is the developed experiment, the application of which in the teaching process is verified by the team and consequently provided to users over the Internet. An important stage in the fur-

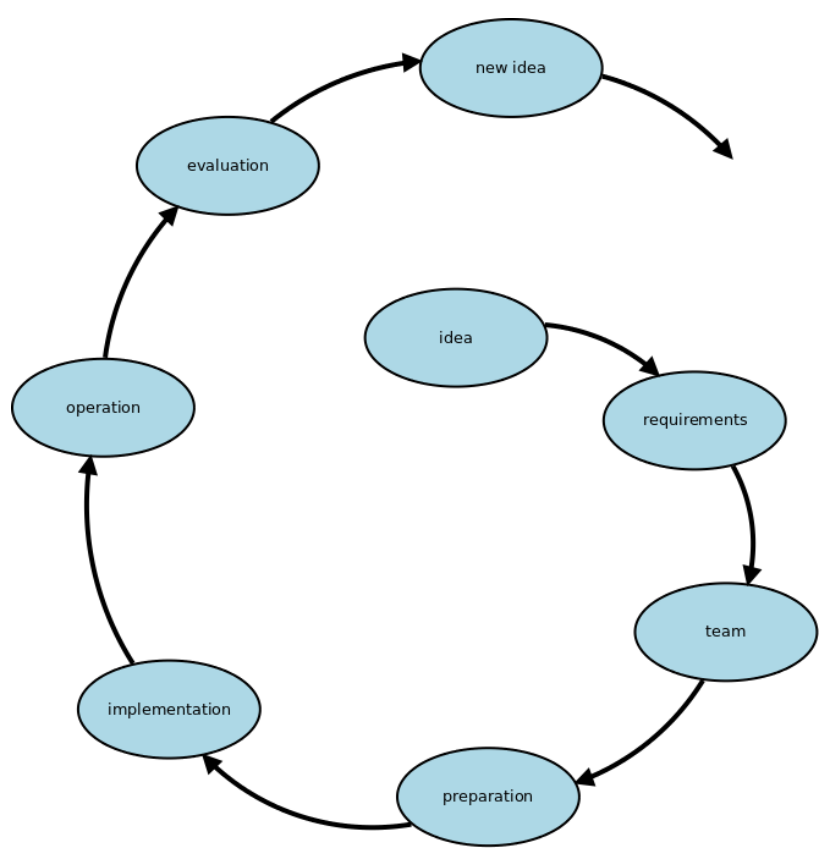

Figure 2. Live cycle of remote experiment. 
ther development of the experiment is evaluation of the operation associated with the design of innovative ideas and their implementation in the next development cycle.

In order for the remote experiment not to become a short-term concern, it is necessary so that the operator would solve and ensure the continued development and innovation based on evaluation of their own experience and users feedback. Therefore, we consider it important, so that the operator would ensure continuous care in the remote experiment and its innovation.

This requirement is well reflected and expressed by the spiral scheme of development, operation and innovation of remote real experiment. Operation and innovation of remote real experiments following the mentioned scheme makes provision for the long-term care and innovation of such experiments in remote laboratories.

\section{REFERENCES}

[1] M. Abdulwahed and Z. K. Nagy, "The TriLab, a novel ICT based triple access mode laboratory education model", in Computers \& Education, vol. 56, no. 1, pp. 262-274, 2011

[2] M. Aburdene, E. Mastascusa, and R. Massengale, "A proposal for a remotely shared control systems laboratory", in Frontiers in Education Conference. Twenty-First Annual Conference Engineering Education in a New World Order Proceeding, West Lafayette, IN, USA, pp. 589-592. 1991

[3] G. R. Alves, "Large and small scale networks of remote labs: a survey", in Advances on Remote Laboratories and E-learning Experiences. University of Deusto, s. 15-34. 2007

[4] I. Eikaas, Ch. Schmid, B. A. Foss and D. Gillet, "A Global Remote Laboratory Experimentation Network and the Experiment Service Provider Business Model and Plans", in Modeling, Identification and Control, vol. 24, no. 3, pp. 159-168, 2003 http://dx.doi.org/10.4173/mic.2003.3.2

[5] A. Ferrero, S. Salicone, C. Bonora and M. Parmigiani, "ReMLab: A Java-Based Remote, Didactic Measurement Laboratory", in IEEE transactions on instrumentation and measurement, vol. 52, no. 3, pp. 710-715, 2003 http://dx.doi.org/10.1109/TIM.2003. $\underline{814695}$

[6] A. Kara, M. E. Ozbeka and N. E. Cagiltaya "Maintenance, sustainability and extendibility in virtual and remote laboratories", in Procedia - Social and Behavioral and Behavioral Sciences, vol. 28, pp. 722-728, 2011
[7] F. Lustig, "Jak si jednoduše postavit vzdálenou laborator na internetu", 2009, 02. Sep. 2011, http://kdf.mff.cuni.cz/veletrh/ sbornik/Veletrh_09/09_19_Lustig.html

[8] Z. Lustigová and F. Lustig, "A New Virtual and Remote Experimental Environment for Teaching and Learning Science", in A New Virtual and Remote Experimental Environment for Teaching and Learning Science, 2009, pp. 75-82.

[9] J. Ma and J. V. Nickerson, "Hands-On, simulated, and remote laboratories: A comparative literature review", in ACM Computer Surveys, vol. 38, no. 3, pp. 1-24, 2006 http://dx.doi.org/ $\underline{10.1145 / 1132960.1132961}$

[10] F. Michau, S. Gentil and M. Barrault, "Expected benefits of webbased learning for engineering education: examples in control engineering" in European Journal of Engineering Education, vol. 26, no. 2, pp. 151-168, 2001 http://dx.doi.org/10.1080/ $\underline{03043790110034410}$

[11] Z. Nedic, J. Machotka and A. Nafalski, "Remote laboratories versus virtual and real laboratories", in Proceedings of the 33rd Annual Frontiers in Education Conference, Boulder. pp. T3E.1T3E.6, 2003

[12] R. Pastor, J. Sánches and S. Dormido, "An XML-based framework for the Development of Web-based Laboratories focused on Control Systems Education", in International Journal of Engineering Education 2003, vol 19, no. 3, pp. 445-454

[13] C. Salzmann and D. Gillet, "Challenges in Remote Laboratory Sustainability", in International Conference on Engineering Education, Coimbra, Portugal, Sep. 3-7 2007

[14] F. Schauer, M. Ožvoldová and F. Lustig, "Integrovaný e-learning - nová metóda výučby demonštrovaná na príklade kmitov", in Vzdelávanie v zrkadle doby, Nitra: PF UKF, 2006, pp. 228-234

[15] T. Kozík, G. Bánesz, D. Lukáčová, M. Šebo, V. Tomková, I. Handlovská, P. Kuna and M. Šimon, "Video Conference Systems in Educational Applications", PF UKF Nitra: 2011, p. 176

\section{AUTHORS}

T. Kozík is a Professor at the Department of Technology and Information Technology of Constantine the Philosopher University, Nitra, Slovak Republic (tkozik@ukf.sk).

M. Šimon is a $\mathrm{PhD}$. student at the Department of Technology and Information Technology of Constantine the Philosopher University (marek.simon@ucm.sk).

This article is a modified and extended version of a paper presented at the International Conference ICL IGIP 2012, held 26-28 September 2012 in Villach, Austria. Manuscript received 21 November 2012. Published as submitted by the authors 24 January 2013 